RESEARCH REPORT

\title{
Occupational stress and incidence of sick leave in the Belgian workforce: the Belstress study
}

\author{
M Moreau, F Valente, R Mak, E Pelfrene, P de Smet, G De Backer, M Kornitzer
}

J Epidemiol Community Health 2004;58:507-516. doi: 10.1136/jech.2003.007518

See end of article for authors' affiliations

Correspondence to:

Correspondence to:
Dr M Moreau, Department of Epidemiology and Health Promotion, School of Public Health, Université Libre de Bruxelles, Campus Erasme, CP 595, Route de Lennik 808, B-1070 Brussels, Bélgium; Michel. Moreau@ulb.ac.be

Accepted for publication 16 July 2003
Context: Sick leave is a major problem in public health. The Karasek demands/control/social support/ strain (JDCS) model has been largely used to predict a wide range of health outcomes and to a lesser extent sickness absence.

Study objective: The aim of the study was to test the predictive power of the JDCS model in relation with one year incidence of sick leave in a large cohort of workers.

Design and setting: Cohort study conducted between 1994 and 1998 in 25 companies across Belgium. Participants: A total of 20463 workers aged 35 to 59 years were followed up for sick leave during one year after the baseline survey.

Outcomes: The outcomes were a high sick leave incidence, short spells ( $\geqslant 7$ days), long spells ( $\geqslant 28$ days), and repetitive spells of sickness absence ( $\geqslant 3$ spells/year).

Main results: Independently from baseline confounding variables, a significant association between high strained jobs with low social support and repetitive spells of sickness absence was observed in both sexes with odds ratios of $1.32(99 \% \mathrm{Cl}, 1.04$ to 1.68$)$ in men and $1.61(99 \% \mathrm{Cl}, 1.13$ to 2.33$)$ in women. In men, high strained jobs with low social support was also significantly associated with high sick leave incidence, and short spells of sick leave with odds ratios of $1.38(99 \% \mathrm{Cl}, 1.16$ to 1.64$)$ and $1.22(99 \% \mathrm{Cl}$, 1.05 to 1.44 ) respectively.

Conclusions: Perceived high strain at work especially combined with low social support is predictive of sick leave in both sexes of a large cohort of the Belgian workforce.
$\mathrm{S}$ ome studies have suggested that occupational stress is related to ill health and outcomes such as absenteeism..$^{12}$ At present, virtually all researchers agree that job stress results from the interaction of the worker and the working conditions and that both are relevant in evaluating stress. However, in a public health approach, environment is considered to be the main determinant of stress. ${ }^{3}$ One of the most influential models in research on the relation between working conditions and health is the Karasek job-demandcontrol-social support (JDCS) model. ${ }^{2}{ }^{4}$ In contrast with stress models developed previously, the JDCS model postulates that psychological strain, and subsequent illness, result from the interaction of two types of job characteristics: psychological demands of the work situation (stressors) and environmental moderators such as control and social support over those demands. Psychological job demands include several stressors affecting work and are felt to be the primary source of stress: perception of the workload, the work rhythm, and possible conflicting demands. Job control or decision latitude on the other hand includes control over use of skills, time allocations, and organisational decisions. ${ }^{2}$ Social support includes support received from colleagues and superiors. ${ }^{5}$ The main hypothesis of the JDCS model states that people in occupations with high psychological demands and low control or "strain hypothesis" are at increased risk for physical and psychological symptoms, coronary heart disease, sick leave, job and life dissatisfaction, and medication use ("strain hypothesis"). ${ }^{2}$ Jobs having this particular combination are identified as high strained work in contrast with relaxed jobs that combine low demands and high control. The worst combination, iso-strain-high demands, low control, and low support-would have the most adverse health consequences. In that way, the model presents a clear prediction of the work conditions associated with stress ${ }^{3}$ and provides starting points for improvement of employee health by way of job redesign. ${ }^{2} 6$

Many studies using the JDCS model have shown significant association between job characteristics on one hand and coronary heart disease, ${ }^{7-10}$ hypertension, ${ }^{10-13}$ psychological disorder and health status and functioning, ${ }^{14}{ }^{15}$ on the other. Few studies tested the model to predict sick leave. ${ }^{16-22}$

In Belgium, all workers are entitled to medical insurance and to benefit from that, a certificate from a medical doctor is required for all spells of more than one day of absence. Thus workers are consulting for symptoms and for signs related to either organic or functional (so called psychosomatic) diseases. A full salary is guaranteed for white collars during the first month and during 14 days for the blue collars. In that way, medically certified absence is an important and a convenient measure of workers' health. However, as health has a social and psychological dimension, sick leave is also influenced by psychosocial circumstances.

Being also an indicator of productivity, sick leave is at the intersection of economy, clinical medicine, occupational medicine, and public health.

To our knowledge, our study is one of the largest prospective studies that examines the relations between self report job characteristics and objective measures of sick leave in a large multi-occupational and multi-sectorial cohorts of both sexes, taking into account a large number of potential confounding variables.

\section{METHODS}

As the design and methods of the study have been described in detail elsewhere, ${ }^{1423}$ we will only summarise them.

The field work in 25 large companies or public administrations across Belgium has been conducted in the period between 1994 and 1998. Of all those on the payroll, a total of 
21419 subjects aged 35-59 accepted to participate in this study, which represents $48 \%$ of all eligible subjects.

The main variables below were recorded by a self administered questionnaire:

Sociodemographic: age, sex, marital status, level of education, mother tongue and country of birth.

Occupation: job title was classified using the International Standard Classification of Occupations (ISCO-88) ${ }^{24}$ divided in three categories [ISCO 1-2, 3-5, and 7-9].

Both level of education and occupation are used as proxy for the socioeconomic status. ${ }^{25}$

Health symptoms and presence of longstanding diseases: presence of angina, respiratory problems, ${ }^{26}$ and history of diabetes.

Health perception: the "current health index" (CHI) is a score computed from the VOEG scale (Vragenlijst Over Ervaren Gezondheid) [questionnaire on health perception], a Dutch scale built up from 13 closed questions each having two outcomes (yes $=1 / n o=0$ ) and thus adding up to a scale between 0 and $13 .{ }^{27}$ The scale was categorised in tertiles.

Smoking habits and alcohol consumption: the standardised questionnaire from the MONICA study was used. ${ }^{28}$

Job characteristics: Karasek's questionnaire ${ }^{29}$ with a total of 26 standardised items. Questions include nine on psychological job demands, nine questions on control or decision latitude, and eight on global social support at work. Each item has four closed possible answers: "fully disagree"; "disagree"; "agree"; "fully agree". The questionnaire has been translated into French, back translated into English, and validated by R Karasek. A Dutch version has been also translated and tested in a pilot study. We used an algorithm to replace up to one missing value per scale: this missing value was given the mean score computed from the set of remaining valid scale items for that particular respondent picking up 5\% more valid cases at most. ${ }^{30}$ These scales proved to contain acceptable internal consistency ( $\alpha$ between 0.66 and 0.87 in men and between 0.66 and 0.88 in women) and scale validity in the Belstress cohort. ${ }^{31}$ For the univariate analyses, we categorised the different basic scales in quartiles separately for men and women. For the construction of the two scales "strain" and "iso-strain", we dichotomised the basic scales using sex specific medians. Jobs with low demands and high control are referred to as "relaxed", those with low demands and low control as "passive", those with high demands and high control as "active", and finally those with high demands and low control as "strained". Jobs with high demands, low control, and low social support are referred to as "high strained with low support". Jobs with low demands, low control, and low social support are referred to as "passive with low support".

Depression: the Iowa short version (11 items) of the original CES-D scale ${ }^{32}$ developed by Kohout et al was used. This short version has been validated in elderly subjects ${ }^{33}$ and in women. ${ }^{34}$ This variable has been categorised in tertiles.

Social support outside work: the most widely accepted scale of social support outside work since the seminal paper of Berkman and Syme in 1979 was used. ${ }^{35}$

Variables listed below were recorded during a clinical examination. For more details, see Coetsier et al 1996. ${ }^{36}$

- Anthropometric data: height, weight from which body mass index was computed $\left(\mathrm{kg} / \mathrm{m}^{2}\right)$.

- Blood pressure increase (yes/no): hypertension was define as having a systolic blood pressure above 140 and/or a diastolic blood pressure above 90 with or without treatment.

- Electrocardiogram: the CHD prevalence at baseline was assessed using the Minnesota code. ${ }^{37}$ Subjects having a code $\mathrm{I}_{1,2,3}$ or/and IV ${ }_{1,2,3}$ or/and $\mathrm{V}_{1,2}$ or VII ${ }_{1}$ were considered as possible or probable "ischaemic ECG" at baseline.

- Biology: total cholesterol dichotomised $(\leqslant 5.0 \mathrm{mmol} / \mathrm{l}$ and above).

Sick leave: all workers who participated in the baseline examination agreed to be screened for sick leave. Computerised sickness absence records were obtained from 24 of 25 companies during 12 months after the baseline examination. Length of spells were computed on a calendar basis. Partial days off of work were counted as full days. As the recording of sick leave in Belgium is strictly ruled under law requiring medical certification and is related to the management of salaries, we may not expect much incorrect reporting in this respect.

All the workers with a follow up less than one year (deceased persons, (pre)-retirement, dismissals, resignation, lost to follow up) were excluded from the analyses. We excluded also absenteeism attributable to maternal leave. Finally a total of 20463 workers (15 557 men and 4906 women) were screened for sick leave during a complete year. As spells of one day of sickness absence do not require any medical certificate, we excluded them from the computing of the different outcomes. Centile 75 (C75) of the distribution of the total annual sickness days was used as cut off to classify the workers with a high one year incidence rate of sick leave. The C75 for men and women was 9 and 13 days respectively. As different types of sick leave are related to different problems, ${ }^{19} 3839$ we defined more specific end points such as short spells (at least one short spell ( $\geqslant 7$ days) per year), long spells (at least one long spells ( $\geqslant 28$ days) per year), and repetitive spells of sick leave (at least three spells per year). Table 1 details the number of participants across each of the outcomes.

To control for a possible type I error due to the multiple analyses performed, we used a level of significance of $1 \%$ $(\alpha=0.01)$ in all analyses. Accordingly $99 \%$ confidence intervals (99\% CI) were calculated. Age adjusted ORs and their 99\%CI were calculated for men and women separately using logistic regression. Multiple logistic regression was used to examine associations between work characteristics and high sick leave incidence, short spells, and repetitive spells of sickness absence. As long spells were comparatively rare events, a modelling incidence approach such as Poisson regression was used to examine the associations between this outcome and job characteristics. ${ }^{40-42}$ We tested three models for the four outcomes: the first one (model 1) took into account age, occupation, education, marital status, place of birth, mother tongue, social support outside the work, smoking, and alcohol consumption. In addition to these variables, the second model (model 2) took into account objective health status variables (biological variables such as blood pressure, cholesterolaemia, body mass index, presence of longstanding illness, and symptoms like cough assessed by questionnaire and coronary heart disease assessed by ECG and questionnaire); in the last one (model 3), we added the health perception (CHI) and the depression status (figures 1 , 2 , and 3). In the multivariate analyses, $15 \%, 15.5 \%$, and 22.4 $\%$ of the total subjects followed up for sick leave had incomplete data in model 1, 2, and 3 respectively. Missing values for health perception, Karasek's scale, social support outside the work, depression, and ISCO account for $8.5 \%$, $8.0 \%, 3.9 \%, 3.5 \%$, and $2.9 \%$ respectively of the total subjects followed up for sick leave. Logistic regression analyses were done using SPSS 10.0 for Windows and the "Hosmer and Lemeshow" test has been used to test the fitting of the models. ${ }^{43}$ For the Poisson regression analyses, we used the statistical package SAS. For short spells, the deviance was largely above the number of degree of freedom indicating a 


\begin{tabular}{|lll|}
\hline Table 1 Number (\%) of participants across different outcomes & \\
\hline & Men $(\mathbf{n}=15557)$ & Women $(\mathbf{n}=4906)$ \\
\hline $\begin{array}{l}\text { Number of participants with a total number of sickness absence } \\
\text { days } \geq \text { C75 }\end{array}$ & $3949(25.4)$ & $1306(26.6)$ \\
$\begin{array}{l}\text { Number of participants with at least one short spell of sickness } \\
\text { absence }\end{array}$ & $5867(37.7)$ & $2340(47.7)$ \\
$\begin{array}{l}\text { Number of participants with at least one long spell of sickness } \\
\text { absence }\end{array}$ & $1018(6.5)$ & $443(9.0)$ \\
$\begin{array}{l}\text { Number of participants with repetitive spells of sickness absence } \\
\text { Number of participants without any sickness absence days }\end{array}$ & $1538(9.9)$ & $781(15.9)$ \\
\hline
\end{tabular}

poor fit of the model whereas the deviance for long spells was close to $1 .^{4042}$

The study has been approved by the medical ethics committee of the faculty of medicine of the Université Libre de Bruxelles.

\section{RESULTS}

\section{Univariate analysis}

There was a clear association between work characteristics and high sick leave incidence ( $\geqslant \mathrm{C} 75)$ as well as short, long, and repetitive spells of sick leave. Men who reported low levels of control at work (quartile 1), have a 2.52-fold increase in the age adjusted risk of having high rate of sick leave $(\geqslant C 75)$ compared with those who reported high levels of control (quartile 4) (table 2). For short, long, and repetitive spells of sick leave, we found a 1.66-fold, 3.29-fold, and 2.71fold increase in the age adjusted risks respectively. Lack of social support at work was positively associated with absenteeism: odds ratios ranged from 1.38 for long spells to 1.68 for repetitive spells.
For women, the same pattern was found for social support at work but less pronounced for job control (table 3).

Compared with relaxed jobs, high strained jobs were associated with significant increase in age adjusted sick leave outcomes in both genders: in men, odds ratios ranged from 1.43 (short spells) to 2.01 (long spells) and in women from 1.37 (short spells) to 1.82 (repetitive spells). Compared with relaxed jobs, passive jobs were associated with a significant increase of all sick leave outcomes in men and with high sick leave incidence and repetitive spells in women. As compared with all other jobs combined, high strained and passive jobs with low levels of social support at work were associated with a significant increase of almost all sick leave outcomes in both sexes.

\section{Multivariate analysis}

In men, adjusting for other potential confounders than age (model 1) reduced the association between job characteristics and absenteeism but the association remained significant.

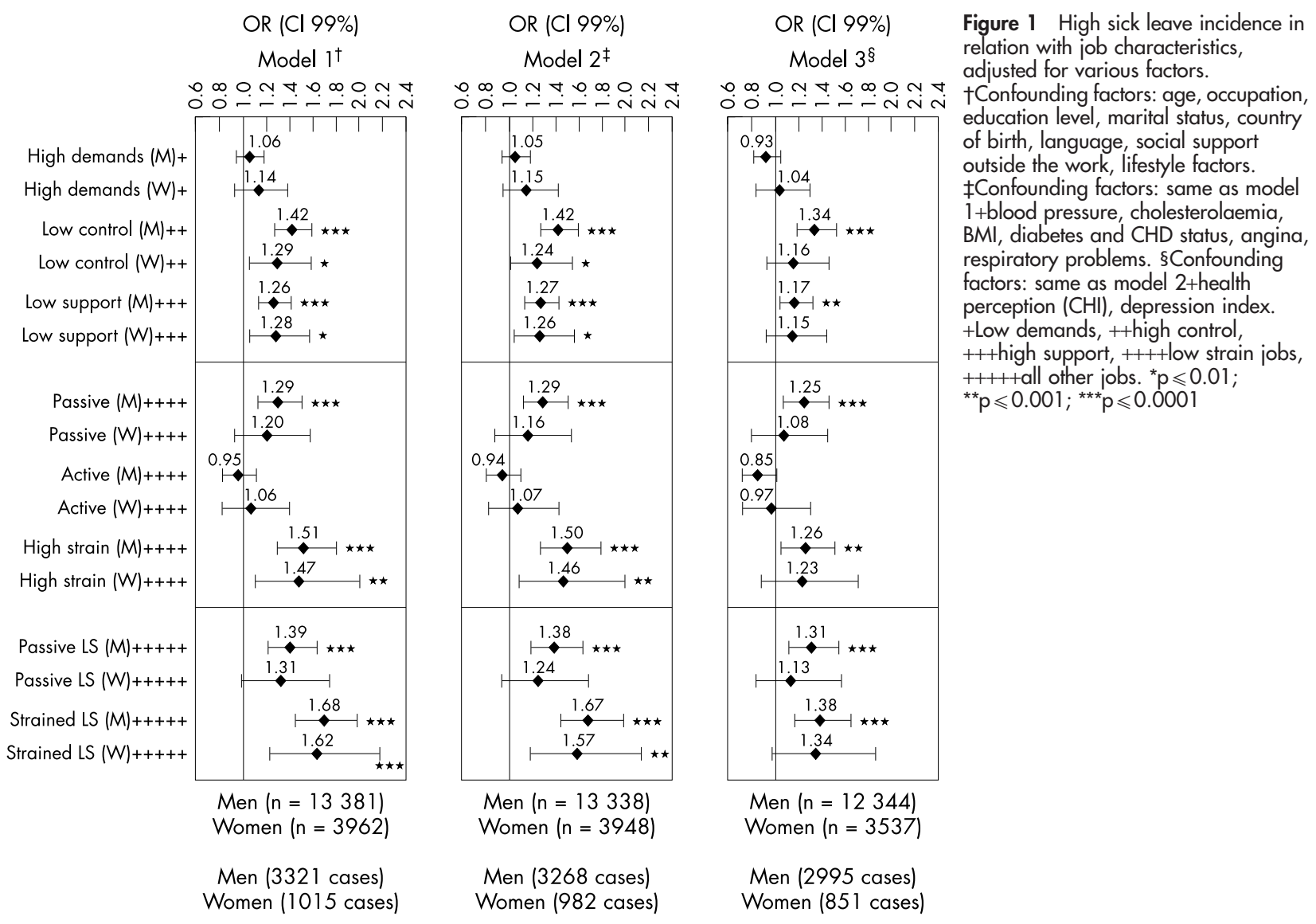



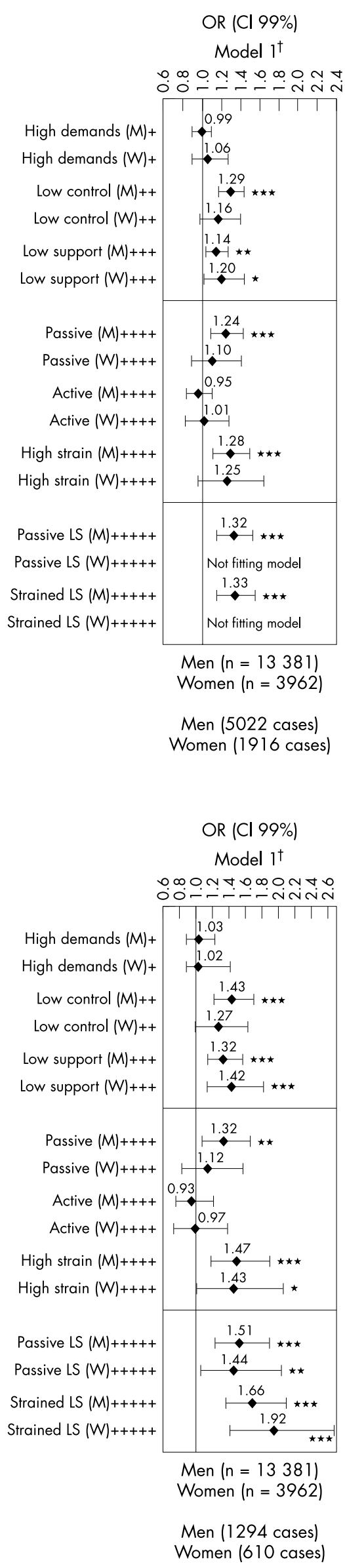

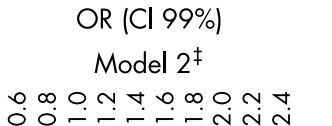

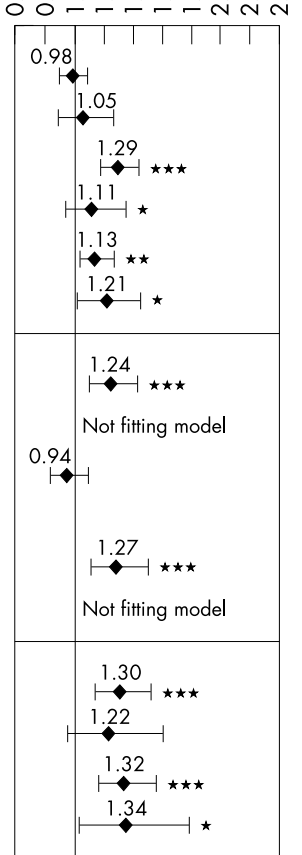

Men $(n=13338)$

Women $(\mathrm{n}=3948)$

Men (4954 cases) Women (1871 cases)
OR (Cl 99\%)

Model $3^{\S}$

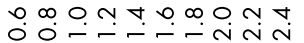

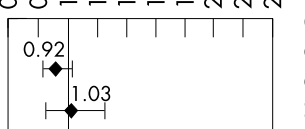

Figure 2 Short spells of sick leave in relation with job characteristics, adjusted for various factors.

†Confounding factors: age, occupation, education level, marital status, country of birth, language, social support outside the work, lifestyle factors. †Confounding factors: same as model $1+$ blood pressure, cholesterolaemia, $\mathrm{BMI}$, diabetes and CHD status, angina, respiratory problems. §Confounding factors: same as model 2+health perception (CHI), depression index. +Low demands, ++high control, +++high support, ++++low strain jobs, ++++ all other jobs. ${ }^{*} \mathrm{p} \leqslant 0.01$; ${ }^{* *} \mathrm{p} \leqslant 0.001 ;{ }^{* * *} \mathrm{p} \leqslant 0.0001$.

OR (Cl 99\%)

Model $2^{\ddagger}$

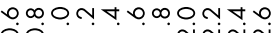

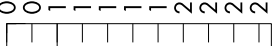

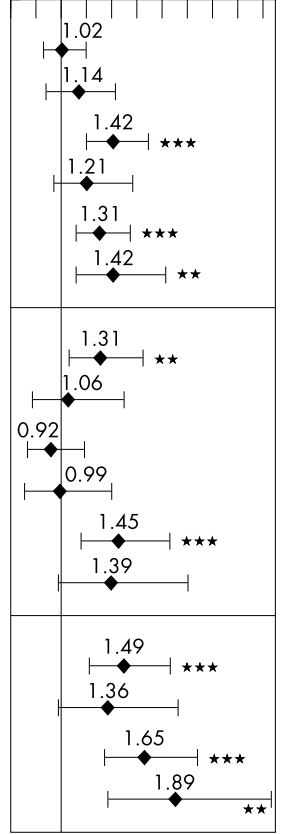

Men ( $n=13338$ )

Women $(n=3948)$

Men (1275 cases) Women (593 cases)
OR (Cl 99\%)

Model $3^{\S}$

on

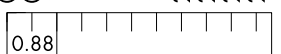
0.88

1.09

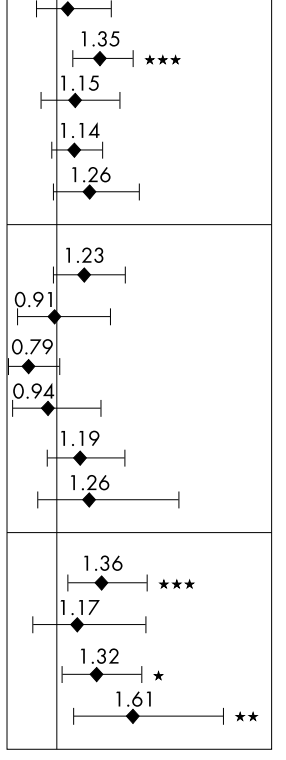

Men ( $\mathrm{n}=12344$ )

Women $(\mathrm{n}=3537)$

Men (1152 cases)

Women (514 cases)
Figure 3 Repetitive spells of sick leave in relation with job characteristics, adjusted for various factors.

*Confounding factors; age, occupation, education level, marital status, country of birth, language, social support outside the work, lifestyle factors; tconfounding factors: same model $1+$ blood pressure, cholesterolaemia, $\mathrm{BMI}$, diabetes and CHD status, angina, respiratory problems; łconfounding factors, same as model 2+health perception (CHI), depression index. +Low demands, ++high control +++high support, ++++low strain jobs, +++++ all other jobs. ${ }^{*} p \leqslant 0.01$; ${ }^{* *} p \leqslant 0.001 ;{ }^{* * *} p \leqslant 0.0001$. 


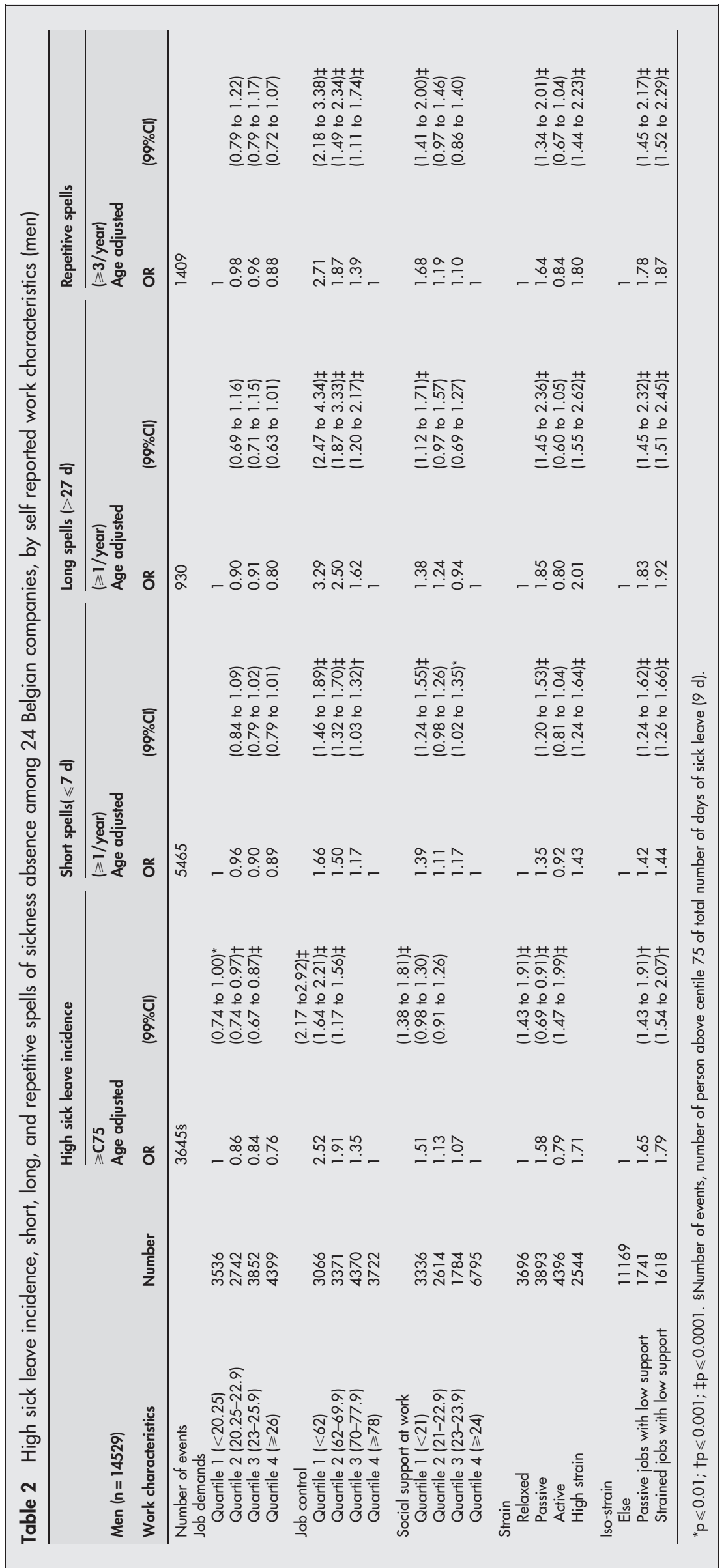




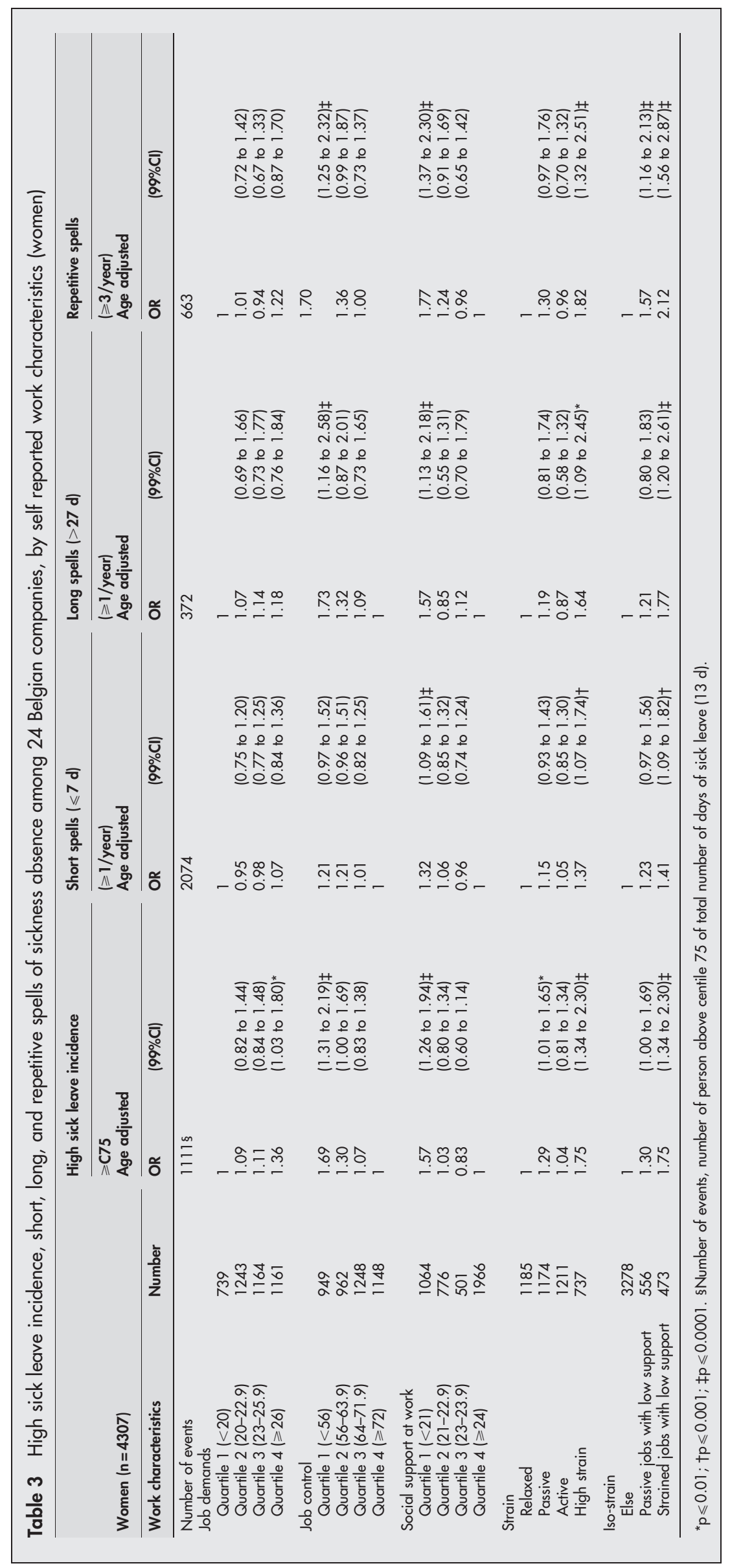


Table 4 Long spells of sickness absence and job characteristics, adjusted for various confounding factors by Poisson regression

\begin{tabular}{|c|c|c|c|}
\hline \multirow[b]{3}{*}{ Iso-strain } & Model $1^{*}$ & \multirow{3}{*}{$\begin{array}{l}\text { Model 2† } \\
\text { Adjusted } \\
\text { RR } 99 \% \mathrm{Cl}\end{array}$} & \multirow{3}{*}{$\begin{array}{l}\text { Model 3¥ } \\
\text { Adjusted } \\
\text { RR 99\% CI }\end{array}$} \\
\hline & \multirow{2}{*}{$\begin{array}{l}\text { Adjusted } \\
\text { RR } 99 \% \mathrm{Cl}\end{array}$} & & \\
\hline & & & \\
\hline Men & (851 cases $n=13381$ ) & (847 cases $n=13338$ ) & (775 cases $n=13344$ ) \\
\hline No & 1 & 1 & 1 \\
\hline Passive jobs with LSS & 1.39 (1.09 to 1.78$)$ & 1.39 (1.09 to 1.77$)$ & $1.32(1.02$ to 1.70$)$ \\
\hline Strained jobs with LSS & $1.69(1.33$ to 2.16$)$ & $1.66(1.30$ to 2.12$)$ & $1.42(1.09$ to 1.85$)$ \\
\hline Women & (333 cases $n=3962$ ) & ( 329 cases $n=3948$ ) & ( 279 cases $n=3537$ ) \\
\hline No & 1 & 1 & 1 \\
\hline Passive jobs with LSS & 1.25 (0.83 to 1.89$)$ & $1.22(0.81$ to 1.85$)$ & 1.08 (0.68 to 1.72$)$ \\
\hline Strained jobs with LSS & 1.70 (1.16 to 2.50$)$ & $1.64(1.11$ to 2.42$)$ & $1.33(0.86$ to 2.06$)$ \\
\hline
\end{tabular}

${ }^{*}$ Confounding factors, age, occupation, education level, civil status, language (French-Dutch), social support at home, smoking, social support at work; †confounding factors, idem+blood pressure, cholesterolaemia, BMI, diabetes and CHD status (angina and/or ECG), respiratory problems; $¥$ confounding factors, idem+health perception $(\mathrm{CHI})$, depression index.

Further adjustment for objective health variables (model 2) had minimal effects on these associations. In contrast, further adjustment for health perception and depression status simultaneously (model 3) reduced considerably the relation between job characteristics and high sick leave incidence, short, long, and repetitive spells of sickness absence. The relation between job characteristics and short spells was the least reduced in model 3.

For instance, in model 1 in men, when compared with jobs with high levels of control, jobs with low levels of control increased the risk of high sick leave incidence, short, and repetitive spells of sick leave with ORs of 1.42 (99\% CI, 1.27 to 1.59 ), 1.29 (99\% CI, 1.16 to 1.43 ), and 1.43 (99\% CI, 1.21 to 1.69) respectively. In the second model, the ORs are similar whereas in the third model, ORs were reduced to 1.34 (99\% CI, 1.19 to 1.52 ), 1.27 (99\% CI, 1.14 to 1.42 ), and 1.35 (99\% $\mathrm{CI}, 1.13$ to 1.61$)$ respectively.

In model 1 in men, when compared with all other jobs combined, high strained jobs with low levels of social support at work increased the risk of high sick leave incidence with ORs of 1.68 (99\% CI, 1.43 to 1.96). In the second model, the ORs are similar whereas in the third model, ORs were reduced to 1.38 (99\% CI, 1.16 to 1.64 ). The same pattern was also found for short and repetitive spells. When using Poisson regression for long spells, we observed also the same pattern (table 4). Thus compared with all other jobs combined, men with high strained jobs with low levels of social support have an increased risk of long spells with RRs of 1.69 ( 1.33 to 2.16 ), 1.66 ( 1.30 to 2.12 ), and 1.42 ( 1.09 to 1.85 ) in model 1 , 2 , and 3 respectively.

In women, we found the same patterns but only repetitive spells of sick leave were significantly associated with low levels of job control and high strained jobs with low levels of social support at work in the saturated model. For other end points, associations were not significant although in the same direction.

\section{Attributable fraction}

From the ORs obtained in the multivariate analyses (model 1) and the prevalence of jobs with low control, we estimated the impact of improving job control on incidence of sick leave (number of sick days above C75) by calculating the attributable fraction among exposed workers and multiplying it by the prevalence of exposition. In men, sick leave incidence (number of sick days above C75) could be reduced by $12.4 \%$ if low job control could be eliminated that is to say 1265 days per year and per 1000 workers. In the same way, sick leave incidence in women could be reduced by $10.6 \%$ if low job control could be eliminated that is to say 1329 days per year and per 1000 workers.

\section{Sensitivity analysis}

Sensitivity analyses using the C60 of the distribution of the total annual sickness days (four days in men and seven days in women) as well as other definition of short spells ( $\leqslant 3$ days) and long spells ( $\geqslant 10$ days) has been performed (model l) and gave in general similar results. For instance in men and women, compared with all other jobs, high strained jobs with low social support were associated with an increased risk of having high sick leave incidence ( $\geqslant \mathrm{C} 60$ ) with an OR of 1.67 (99\% CI, 1.44 to 1.94) and 1.80 (99\% CI, 1.38 to 2.36 ) respectively. For short spells, we observed OR of 1.35 (99\% CI, 1.15 to 1.57 ) and 1.27 (99\% CI, 0.96 to 1.66 ) and for long spells, 1.62 (99\% CI, 1.36 to 1.93$)$ and 1.48 (1.09 to 2.00 ) respectively.

\section{Missing data}

Finally, in table 5, we compared people included in model 3 with those excluded from this model because of incomplete data. Compared with the group with complete data, means scores of demands and control were significantly lower in the "missing group" whereas means scores of social support and depression were significantly higher. Health perception was not significantly different in the two groups. As depression is positively associated with both job stress and sick leave, results in model 3 are probably a little overestimated. To estimate the effect of missing value of the Karasek's scales on the results, we calculated a mean score value of demands, control, and social support by sex, two digit ISCO, and company in the rest of the database. Missing values in the Karasek's scales decreased from $8.0 \%$ to $1.0 \%$ after their replacement by these computed mean scores. Results obtained with these new scores were very similar: OR in model 3 were slightly higher after replacement of missing value in the Karasek's scales except for short spells in men and high sick leave incidence in women. Thus compared with all other jobs, high strained jobs with low social support in men and women were associated with an increased risk of having repetitive spells with an OR of 1.34 (1.07 to 1.68) and 1.68 ( 1.19 to 2.37 ) respectively. For short spells, we observed OR of 1.20 (1.04 to 1.39 ) and 1.25 (0.94 to 1.67$)$ whereas for high sick leave incidence, we observe OR of 1.41 (1.20 to $1.66)$ and 1.31 (0.97 to 1.79 ) respectively.

\section{DISCUSSION}

Previous studies on absenteeism are difficult to compare because of differences in the way job characteristics such as demands were reported: in a subjective $e^{16-192122}$ or objective way. ${ }^{20}$ Moreover, sick leave was either self reported ${ }^{16}{ }^{17} 22$ or not, ${ }^{18-21}$ the point in time of sick leave measurement was either before ${ }^{16}$ or after job stress measurement, ${ }^{17-22}$ the type of 


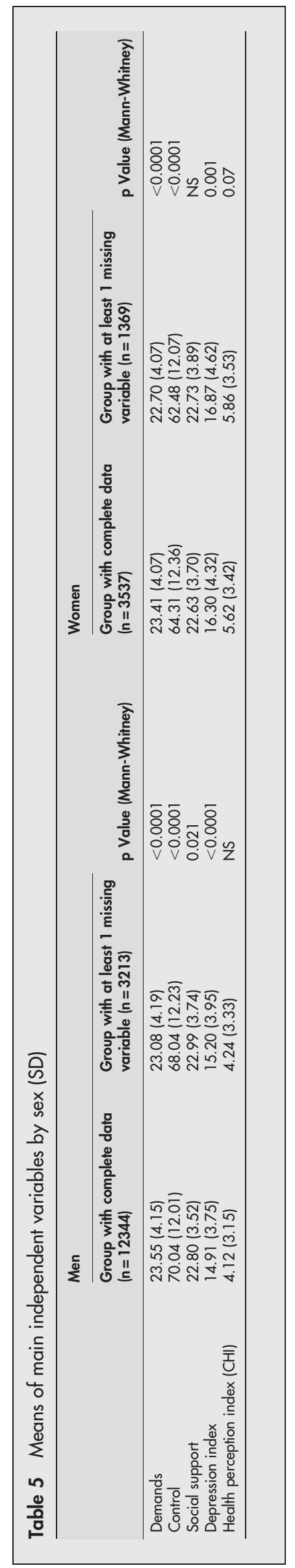

the study was cross sectional ${ }^{161722}$ or prospective $e^{18-21}$ and eventually other measured covariables are different from a study to another.

Nevertheless, our results are consistent with reports of these studies of higher rate of sick leave among male and female workers involved in jobs with low levels of control. ${ }^{16-21}$ As other studies, ${ }^{44} 45$ we found also a significant negative association between social support at work and sick leave in both sexes even after adjustments for a wide range of confounders. However, we did not find any consistent association between job demands and absenteeism in both sexes. Although being felt the primary source of stress, demands are not associated with sick leave. For most occupations today, demands within the workplace rarely exceed the physical and intellectual capabilities of most workers. Thus the source of stress is to be found in work that simultaneously combines high demands and low control. ${ }^{3}$ Another explanation is that the demands scale do not capture all the constraints and should be better conceptualised and expanded.

Like the Whitehall II study, ${ }^{19}$ we found that the relation between job characteristics and sick leave are largely independent of potential confounders (model 1 and 2). Nevertheless, this study, like the others referred above did not adjust for baseline health status, perceived health, and depression although these variables are strongly associated with perception of stressors ${ }^{14}$ and sick leave. ${ }^{18}{ }^{20}$ Conceptually, health, perceived health, and depression are generally considered as mediators between job stressors and sick leave. ${ }^{36}$ On the other hand, objective health status and perceived health or depression could modify the perception of the job stressors. In that way, Ondersma et $a l^{46}$ consider health perception and negative affectivity as a co-manisfestation of a single disposition. After adjustment for objective health variables (model 2), the association between job characteristics and sick leave remained similar. In contrast, further adjustment for self perceived health and depression reduced considerably the strength of the association with the exception of short spells. Yet, the association between job characteristics and sick leave remained significant. We propose two possible explanations: (1) job characteristics are linked to sick leave both indirectly through health or health perception but also directly. One possibility is that absenteeism could be considered as a direct coping behaviour that is a reaction to job characteristics (a behaviour of withdrawal from work $)^{38} 47$ or as Kristensen proposed" $^{22}$ "as a conscious coping behaviour seen in the light of a person's wish to keep his/her health and working capacity". If it is confirmed, clinicians should be aware of this in managing their patients and should take an occupational history including assessment of psychosocial job characteristics; (2) we have not taken into account other important conditions such as asthma, allergies, or other important biological mediating factors between stress and absenteeism such as immunological, biochemical, hormonal, or haemostatic factors (fig 4$){ }^{48}$

The associations between job characteristics and short spells are less influenced by the introduction of health variables in the model (model 3) than for long and repetitive spells. This is consistent with previous studies showing that long term and repetitive spells of sickness absence are best viewed as a measure of morbidity ${ }^{38}{ }^{39}$ whereas short spells are more influenced by psychosocial factors ${ }^{19}$ and problems other than health.

Our findings could also suggest that sick leave may be a reflection of employees' perceptions of their health in response to illness rather than physical health. ${ }^{38} 49$

In contrast with other studies, ${ }^{19}{ }^{20}$ the associations between job characteristics and sick leave is weaker in short spells 


\section{Policy implications}

- The results of this study have political implications at both the public health and labour level.

- Legislation concerning stress management at the workplace was enacted in 1996 in Belgium (Welfare at Work act).

- Practically, means to develop techniques increasing perception of job control and social support at work should be supported by the political authorities of both ministries (Public health and Labour)

- New legislation concerning stress management at the workplace should be proposed adding practical means to reduce job stress, thus increasing wellbeing at the workforce level.

than in long spells but our definitions of short and long spells are different as well as sick leave regulations. In our study, it could suggest that the effect of unfavourable job characteristics on health is more important than on other factors such as job dissatisfaction or boredom.

Iso-strained jobs have been already found associated with poor health ${ }^{50}$ in women in a previous study, but to our knowledge it is the first time that a study shows a significant association between iso-strained jobs and sick leave prospectively. Having high strained jobs or high strained jobs with low support is a major risk factor for sick leave in both sexes. Moreover, in both sexes, the combination of the three scales-job demands, control, and social support-is a better predictor of sick leave than the three scales used separately whatever the outcome analysed.

This study was prospective, relying on external and objective sources for collecting standardised sick leave data. In the 24 companies, sick leave data are gathered for purposes of paying wages and can, therefore, be considered as being both a reliable and a valid measure. Independent and dependent variables were not gathered by the same method, which means that the association observed were not spurious. ${ }^{4}$ Our study population is definitely not representative of the Belgian workforce but as recalled by Kristensen ${ }^{4}$ it is the variation of exposure that matters in analytical studies and not representativity. As all the selected occupations come from the secondary (industrial), tertiary (private services), and fourth sector (public services), they represent different positions in the demand-control-support model leading to a large variance.

As recommended by Liberatos and et al, ${ }^{25}$ all the analyses were done using two measures of socioeconomic status (education and occupation). In contrast with other studies, we were able to control for many confounding factors.

However, several limitation of this study should be discussed. As it is forbidden, for ethical reasons to follow up subjects who refused to participate in an epidemiological study, at least in Belgium, we could not compare people who refused with those who accepted to participate. Therefore an initial selection bias cannot be ruled out and generalisation of results should be taken with some caution. Still the associations observed between predictors and outcomes in the participating cohort remain valid.

As we could not take into account in our analyses previous absenteeism and some other factors such as biochemical, immunological, hormonal, haemostatic, or allergic factors, we cannot exclude that a selection effect occurred. Although to our knowledge this has not been described yet, workers more prone to illness through these factors could select into passive or high strain jobs.

The comparatively large proportion of missing value for some important measurements such as depression, health perception, and the Karasek's scales could also be a limitation. The effect of missing value for depression index gave probably an overestimation of the association between job characteristics and sick leave. Alternatively, adjusting for health and/or perceived health will probably underestimate this association as these co-variables partially mediate between job stressors and sick leave. With regard to missing values for the Karasek's scales, we did not find much change after their replacement.

Because of privacy matters, it was not possible to make the distinction between absenteeism attributable to sickness and to work accident in some companies. For companies where it was possible to do so, work accidents accounted for only $2.9 \%$ of the total number of days, which will probably not influence the results.

Although absenteeism is a complex phenomenon, our study has taken into account only some factors that influence sick leave. Risk factors specific to the work (indispensability at work), informal norms about acceptable levels of absence among colleagues, ${ }^{22}$ family situation attributable to the person or work-home interference, risks factors at the group level, as well as psychological trait factors may be important and should be considered when interpreting our findings.

In addition to examining spells of different duration, it would be useful to examine spells for specific reasons for absence. We are currently further investigating the relation between work characteristics and depression and cardiovascular diseases.

Sick leave being an indicator of morbidity and productivity, the results of this study may have implications in the field of both public health and economy and should help to "rethink" the work and its organisation in Belgium.

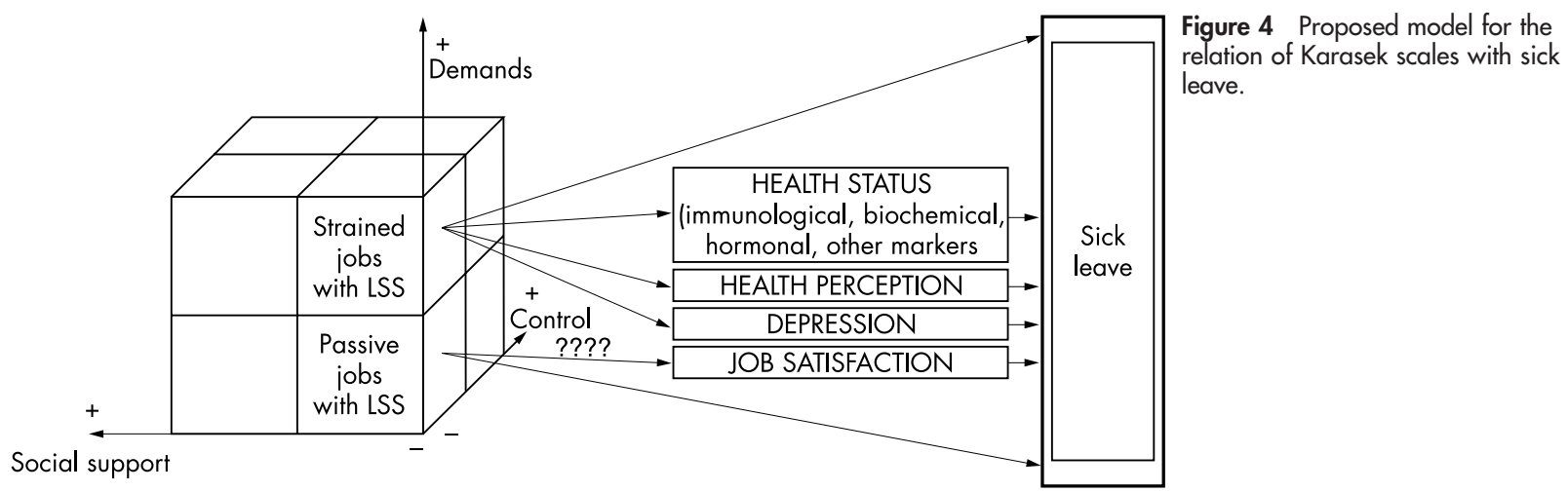


We have shown evidence that job characteristics from the Karasek's model predict absenteeism taking into account potential confounding variables. The next step should be to implement a controlled intervention study or job redesign, affecting favourably decision latitude and social support at work. The impact of their modifications through incidence of sick leave could be analysed and the causal relation between job characteristics and sick leave could be strengthen.

\section{Authors' affiliations}

M Moreau, F Valente, P de Smet, M Kornitzer, Department of Epidemiology and Health Promotion, School of Public Health, Brussels Free University, Belgium

R Mak, E Pelfrene, G De Backer, Vakgroep Maatschappelijke Gezondheidkunde, Universiteit Gent, Belgium

Funding: the study received grants from the National Foundation of Scientific Research (FNRS) and the "Services fédéraux des affaires Scientifiques, Techniques et Culturelles" (SSTC).

Conflicts of interest: none declared.

\section{REFERENCES}

1 Stansfeld S, Bosma H, Hemingway $\mathrm{H}$, et al. Psychosocial work characteristics and social support as predictors of SF-36 health functioning: the Whitehall II study. Psychosom Med 1998;60:247-55.

2 Karasek R, Theorell T. Healthy work-stress, productivity and the reconstruction of working life. London: Harper Collins, 1990:1-381.

3 Baker D. The study of stress at work. Annu Rev Public Health 1985:6:367-81.

4 Kristensen T. The demand-control-support model: methodological challenges for future research. Stress Medicine 1995;11:17-26.

5 Johnson J, Hall E, Theorell T. Combined effects of job strain and social isolation on cardiovascular disease morbidity and mortality in a random sample of the Swedish male working population. Scand J Work Environ Health 1989;15:271-9.

6 Theorell T. How to deal with stress in organizations? - a health perspective on theory and practice. Scand J Work Environ Health 1999;25:616-24.

7 Kristensen T. Job stress and cardiovascular disease: a theoretic critical review. J Occup Health Psychol 1996; 1:246-60.

8 Johnson J, Stewart W, Hall E, et al. Long-term psychosocial work environment and cardiovascular mortality among Swedish men. Am J Public Health 1996:86:324-31.

9 Theorell T, Tsutsumi A, Hallquist J, et al. Decision latitude, job strain, and myocardial infarction: a study of working men in Stockholm. The SHEEP Study Group. Stockholm Heart epidemiology Program. Am J Public Health 1998:88:382-8.

10 Schnall P, Pieper C, Schwartz J, et al. The relationship between 'job strain,' workplace diastolic blood pressure, and left ventricular mass index. Results of a case-control study. JAMA 1990;263:1929-35.

11 Theorell T, de Faire U, Johnson J, et al. Job strain and ambulatory blood pressure profiles. Scand J Work Environ Health 1991;17:380-5

12 Marmot M. Psychosocial factors and blood pressure. Prev Med 1985; 14:451-65.

13 Schnall P, Schwartz J, Landsbergis P, et al. A longitudinal study of job strain and ambulatory blood pressure: results from a three-year follow-up. Psychosom Med 1998;60:697-706

14 Pelfrene E, Vlerick P, Kittel F, et al. Psychosocial work environment and psychological well-being: assessment of the buffering effects in the job demand-control(-support) model in Belstress. Stress and Health 2002; 18:43-56.

15 Johnson J, Hall E, Ford D, et al. The psychosocial work environment of physicians. The impact of demands and resources on job dissatisfaction and psychiatric distress in a longitudinal study of Johns Hopkins Medical School graduates. J Occup Environ Med 1995;37:1151-9.

16 Houtman I, Bongers P, Smulders P, et al. Psychosocial stressors at work and musculoskeletal problems. Scand J Work Environ Health 1994;20:139-45.

17 Karasek R, Gardell B, Lindell J. Work and non work correlates of illness and behaviour in male and female Swedish white collars workers. Journal of Organisational Behavior 1987;8:187-207.

18 North F, Syme S, Feeney A, et al. Explaining socioeconomic differences in sickness absence: the Whitehall II study. BMJ 1993;306:361-6.

19 North F, Syme S, Feeney A, et al. Psychosocial work environment and sickness absence among British civil servants: the Whitehall II study. Am J Public Health 1996;86:332-40
20 Vahtera J, Pentti J, Uutela A. The effect of objective job demands on registered sickness absence spells; do personal, social and job-related resources act as moderators? Work and Stress 1996;10:286-308.

21 de Jonge J, Reuvers $M$, Houtman I, et al. Linear and nonlinear relations between psychosocial job characteristics, subjective outcomes, and sickness absence: baseline results from SMASH. Study on musculoskeletal disorders, absenteeism, stress, and health. J Occup Health Psychol 2000;5:256-68.

22 Kristensen T. Sickness absence and work strain among Danish slaughterhouse workers: an analysis of absence from work regarded as coping behaviour. Soc Sci Med 1991:32:15-27.

23 Coetsier P, De Backer G, De Corte W, et al. Etude belge du stress au travail: aperçu du modèle de recherche et des outils $d^{\prime}$ investigation. [Belgian study of work stress: outline of research model and research tools] Psychologie and Psychométrie 1996:17:17-35.

24 WHO. International standard classification of occupations: ISCO-88. Geneva: WHO, 1990

25 Liberatos $\mathbf{P}$, Link B, Kelsey J. The measurement of social class in epidemiology. Epidemiol Rev 1988;10:87-121.

26 Rose G, Blackburn H, Gillum R, et al. Cardiovascular survey methods. Geneva: WHO, 1982.

27 Dirken JM. Arbeid and gezondheid. Groningen: Wolters-Noordhoff, 1969

28 WHO. Monica manual. Geneva: WHO, 1990.

29 Karasek R, Baker D, Marxer F, et al. Job decision latitude, job demands, and cardiovascular disease: a prospective study of Swedish men. Am J Public Health $1981 ; 71: 694-705$

30 Bosma $\mathrm{H}$, Marmot $M$, Hemingway $\mathrm{H}$, et al. Low job control and risk of coronary heart disease in Whitehall II (prospective cohort) study. BMJ 1997:314:558-65.

31 Pelfrene E, Vlerick P, Mak R, et al. Scale reliability and validity of the Karasek 'Job Demand-Control-Support' model in the Belstress study. Work and Stress 2001;15:297-313

32 Radlof L. The CES-D Scale: a self-report depression scale for research in the general population. Applied Psychological Measurement 1977;1:385-401.

33 Kohout F, Berkman L, Evans D, et al. Two shorter forms of the CES-D Depression Symptoms Index. Journal of Aging and Health 1993;5:179-93.

34 Carpenter J, Andrykowski M, Wilson J, et al. Psychometrics for two short forms of the Center for Epidemiologic Studies-Depression scale. Issues Ment Health Nurs 1998;19:481-94.

35 Berkman L, Syme S. Social networks, host resistance, and mortality: a nineyear follow-up study of Alameda County residents. Am J Epidemiol 1979:109:186-204.

36 Coetsier P, De Backer G, De Corte W, et al. Onderzoeksdesign en instrumentarium van het belgish jobstress onderzoek-Modele de recherche et manuel de travail de l'étude Belge du stress au travail. [Research model and work manual of the Belgian study of work stress] Theoretishe en toegepaste Psychologie 1996;6.

37 Scandinavian Committee on ECG Classification. The "Minnesota Code" for ECG classification. Adaptation to CR leads and modification of the code for ECGs recorded during and after exercise by the Scandinavian Committee on ECG Classification. Acta Med Scand Supp 1967:481:1-26.

38 Marmot $M$, Feeney $A$, Shipley $M$, et al. Sickness absence as a measure of health status and functioning: from the UK Whitehall II study. J Epidemiol Community Health 1995;49:124-30.

39 Szubert Z, Szeszenia-Dabrowska N. [Diagnosis and the reasons for absenteeism among workers with frequent and long-term diseases]. [Abstract]. Med Pr 1990;41:264-9.

40 Frome EL, Checkoway H. Epidemiologic programs for computers and calculators: use of poisson regression models in estimating incidence rates and ratios. Am J Epidemiol 1985;121:309-23.

41 Dobson AJ, Kuulasma K, Eberle E, et al. Confidence intervals for weighted sums of Poisson parameters. Stat Med 1991;10:457-62.

42 Frome EL. The analysis of rates using Poisson regression models. Biometrics 1983;39:665-74

43 Hosmer D, Lemeshow S. Applied logistic regression. New York: Wiley, 1989.

44 Stansfeld S, Rael E, Head J, et al. Social support and psychiatric sickness absence: a prospective study of British civil servants. Psychol Med 1997;27:35-48.

45 Unden A. Social support at work and its relationship to absenteeism. Work and Stress 1996;10:46-61.

46 Ondersma S, Lumley M, Corlis M, et al. Adolescents with inflammatory bowe disease: the roles of negative affectivity and hostility in subjective versus objective health. J Pediatr Psychol 1997;22:723-38.

47 Hill JM, Trist EL. A consideration of industrial accidents as means of withdrawal from the work situation. Human Relations 1955:8:121-52.

48 Kelly S, Hertzman C, Daniels M. Searching for the biological pathways between stress and health. Annu Rev Public Health 1997; 18:437-62.

49 McKenna S, Hunt S, McEwen J. Absence from work and perceived health among mine rescue workers. J Soc Occup Med 1981;31:151-7.

50 Amick B, Kawachi I, Coakley E, et al. Relationship of job strain and iso-strain to health status in a cohort of women in the United States. Scand J Work Environ Health 1998;24:54-61. 